\title{
Using Interactive Power Point Media to Improve The Learning Outcomes of Class V Students
}

\section{Riska Anastiara Sari}

SD Negeri Randuacir 03 anastiriska@gmail.com

\section{Article History}

accepted 01/11/2020

approved 08/11/2020

published 15/11/2020

\begin{abstract}
The purpose of this study to improve the learning outcomes of class $V$ students using interactive Power Point media. Classroom Action Research (CAR) is carried out in three cycles, where each cycle consists of planning, implementing, observing and reflecting. The subjects of this study were students of grade V SD Negeri Randuacir 03 for the 2020/2021 school year, totaling 18 students. The techniques collection data use observation and tests. From the results of this study indicate that the use of interactive Power Point learning media can improve student learning outcomes in Theme 5 Ecosystem Content of Indonesian Language Learning as evidenced by the percentage of completeness of learning outcomes in cycle $167 \%$ to $78 \%$ in cycle II and increases again to $83 \%$ in cycle III.
\end{abstract}

Keywords: Media, interactive power point, the learning outcomes

\begin{abstract}
Abstrak
Tujuan penelitian ini adalah untuk meningkatkan hasil belajar peserta didik kelas $\mathrm{V}$ menggunakan media Power Point Interaktif. Penelitian Tindakan Kelas (PTK) dilaksanakan dalam tiga siklus, dimana setiap siklus terdiri dari perencanaan, pelaksanaan, observasi dan refleksi. Subjek penelitian ini yaitu peserta didik kelas V SD Negeri Randuacir 03 tahun pelajaran 2020/2021 yang berjumlah 18 peserta didik. Teknik pengumpulan data mneggunakan observasi dan tes. Dari hasil penelitian ini menunjukkan bahwa penggunaan media pembelajaran Power Point Interaktif dapat meningkatkan hasil belajar peserta didik pada Tema 5 Ekosistem Muatan Pelajaran Bahasa Indonesia yang dibuktikan dengan presentase ketuntasan hasil belajar pada siklus $167 \%$ menjadi 78\% Pada siklus II dan meningkat lagi menjadi $83 \%$ pada siklus III.
\end{abstract}

Kata kunci: Media, Power Point Interaktif, Hasil Belajar

Social, Humanities, and Education Studies (SHEs): Conference Series https://jurnal.uns.ac.id/shes

p-ISSN 2620-9284

e-ISSN 2620-9292 


\section{PENDAHULUAN}

Belajar adalah kunci utama dalam usaha pendidikan. Pendidikan merupakan hal penting dalam kehidupan manusia dalam rangka mencerdaskan kehidupan bangsa. Sedangkan hasil belajar berperan penting dalam proses pembelajaran. Selain hasil belajar keaktifan peserta didik juga perlu diperhatikan dalam proses pembelajaran. Proses pembelajaran sangat memerlukan keaktifan peserta didik, tanpa adanya keaktifan peserta didik maka pembelajaran akan merasa membosankan. Untuk mencapai itu semua diperlukan kreatifitas guru dalam penggunaan media pembelajaran yang menarik agar mencapai tujuan pembelajaran secara maksimal.

Namun kenyataannya, ada beberapa faktor hambatan untuk mencapai proses pembelajaran yang maksimal. Diantara ada faktor dari dalam diri peserta didik, yaitu hasil belajar peserta didik masih rendah dan juga peserta didik kurang berkonsentrasi saat pembelajaran berlangsung. Hal ini terlihat dari hasil belajar peserta didik lebih dari $75 \%$ di bawah KKM. Selain dari peserta didik ada beberapa faktor yang datang dari guru. Faktor masalah yang datang dari guru diantaranya selama proses pembelajaran guru tidak menggunakan media pembelajaran, selain itu pelaksanaan pembelajaran juga kurang menarik bagi peserta didik.

Untuk mengatasi beberapa masalah yang telah dijabarkan, penggunaan media yang menarik dapat menumbuhkan motivasi belajar peserta didik sehingga akan mempengaruhi hasil belajar mereka. Istilah media itu sendiri berasal dari bahasa latin yang merupakan bentuk jamak dari medium. Secara harfiah bearti perantara atau pengantar. Secara umum diartikan segala sesuatu yang dapat menyalurkan informasi kepada penerima informasi (Arsyad, 2009:3). Peneliti memilih menggunakan media Power Point Interaktif sebagai media pembelajaran dilihat dari sarana dan prasarana yang sudah memadai. Manfaat penggunaan media juga sebagai perangsang anak untuk semangat belajar. Media ini dapat membuat anak tertarik untuk mengikuti pelajaran secara maksimal. Selain itu seperti yang dikemukakan oleh Daryanto (2010:164), yaitu pesan informasi yang dikemas secara visual akan lebih mudah dipahami peserta didik sehingga hasil belajar mereka akan meningkat. Dengan penambahan gambar yang menarik dalam tampilan Powerpoint, maka pesan atau informasi yang disampaikan akan mudah dipahami oleh peserta didik. Dengan bantuan Power Point Interaktif juga dapat membantus eorang guru untuk menampilkan materimateri pelajaran yang sulit ditemukan di dunia nyata. Jadi bisa digambarkan melalui penayangan Power Point Interaktif. Penelitian menggunakan media Power Point sudah pernah dilakukan oleh Erna Kartika dengan judul PTK "Penggunaan Media Power Point Untuk Meningkatkan Hasil Belajar Mata Pelajaran IPS Siswa Di Kelas VI SDN Kaliasin VII Surabaya".

Dengan tayangan Power Point Interaktif, kemampuan mendengarkan dan membaca peserta diidk dapat dikembangkan. Dengan begitu peneliti tertarik untuk melaksanakan penelitian yang berjudul "Penggunaan Media Power Point Interaktif Dalam Peningkatan Hasil Belajar Peserta Didik Kelas V SD Negeri Randuacir 03 Tahun Pelajaran 2020/2021".

Berdasarkan latar belakang masalah di atas, maka perumusan masalah penelitian adalah:

a. Apakah media Power Point Interaktif dapat meningkatkan hasil belajar peserta didik kelas V SD Negeri Randuacir 03?

b. Bagaimana penggunaan media Power Point Interaktif dapat meningkatkan hasil belajar peserta didik kelas V SD Negeri Randuacir 03?

Dari beberapa permasalahan yang sudah dirumuskan di atas, tujuan yang ingin dicapai dari penelitian ini adalah sebagai berikut:

a. Untuk mengetahui Apakah media Power Point Interaktif dapat meningkatkan hasil belajar peserta didik kelas V SD Negeri Randuacir 03 
b. Untuk mengetahui Bagaimana penggunaan media Power Point Interaktif dapat meningkatkan hasil belajar peserta didik kelas V SD Negeri Randuacir 03

\section{METODE}

Penelitian ini merupakan Penelitian Tindakan Kelas (PTK) yang dilaksanakan sebanyak tiga siklus. Setiap siklus dilakukan satu kali pertemuan yang terdiri dari tahap perencanaan, pelaksanaan, observasi, dan refleksi. Waktu pelaksanaan dilakukan pada bulan Oktober sampai November dengan subjek penelitian adalah peserta didik kelas V SDN Randuacir 03 tahun pelajaran 2020/2021 yang berjumlah 18 peserta didik.

Teknik pengumpulan data dengan kualitatif yaitu hasil observasi oleh teman sejawat selama proses pembelajaran berlangsung menggunakan media Power Point Interaktif dan dengan kuantitatif berupa hasil belajar peserta didik mengerjakan soal evaluasi. kesimpulan.

Untuk Teknik analisis data meliputi reduksi data, penyajian data, dan penarikan

\section{HASIL DAN PEMBAHASAN}

Berdasarkan analisis hasil penelitian yang telah diuraikan maka pembahasan pada penelitian sebagai berikut. berikut.

Hasil penelitian menunjukkan peningkatan hasil belajar, terlihat pada table

Diagram 1. Hasil Belajar siklus I, II dan III

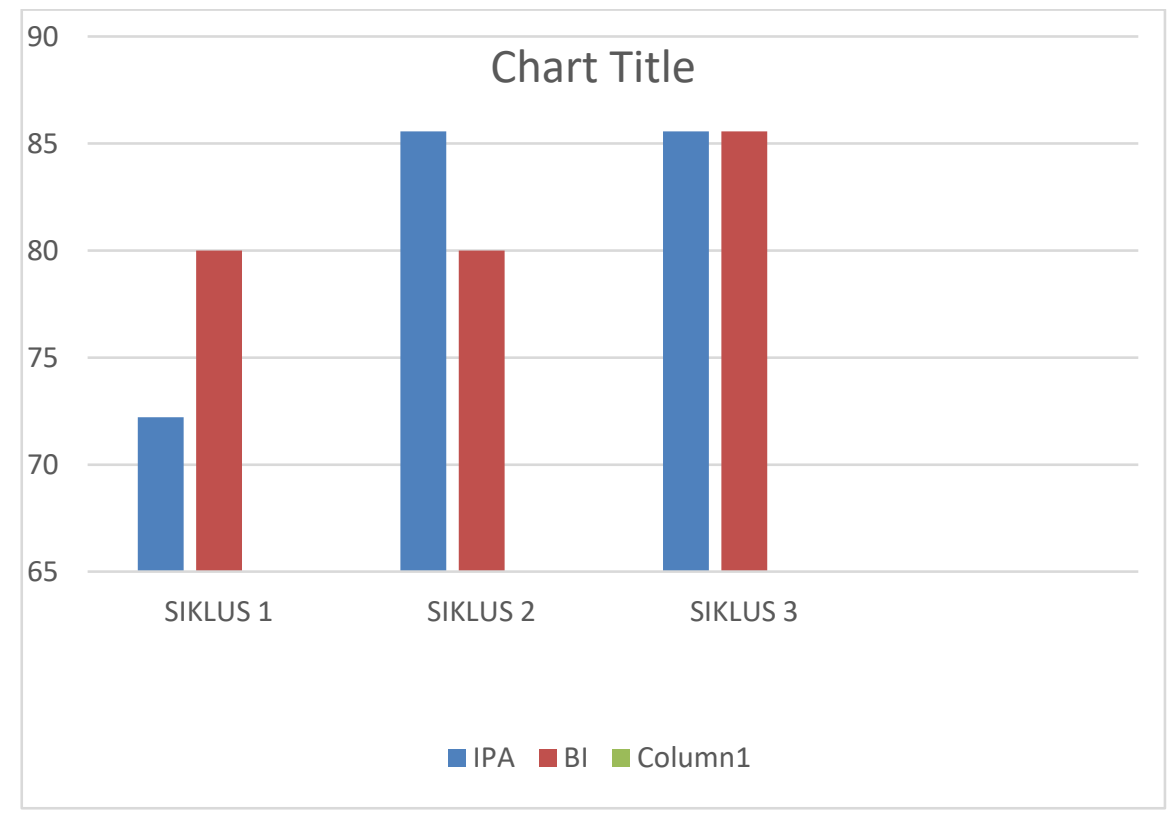

Berdasarkan diagram di atas dapat diketahui bahwa pada siklus satu nilai ratarata peserta didik pada muatan pelajaran IPA adalah 72,22. Namun ketika siklus dua mengalami peningkatan menjadi 85,56 . Untuk siklus tiga tetap bertahan 85,56 . Adapun untuk muatan pelajaran Bahasa Indonesia nilai rata-rata pada siklus satu 80 . Untuk 
siklus dua tetap bertahan 80 . Namun ketika siklus tiga mengalami peningkatan menjadi 85,56 .

Tabel 1. Nilai rata-rata dan presentase ketuntasan belajar

\begin{tabular}{|c|c|c|c|c|c|c|}
\hline & \multicolumn{2}{|c|}{ Siklus 1} & \multicolumn{2}{|c|}{ Siklus 2} & \multicolumn{2}{|c|}{ Siklus 3} \\
\hline & IPA & B.Indo & IPA & $\mathrm{Bl}$ & IPA & B. Indo \\
\hline Hasil Rata-rata & 72,22 & 80 & 85,56 & 80 & 85,56 & 85,56 \\
\hline Presentase ketuntasan & $67 \%$ & $67 \%$ & $89 \%$ & $78 \%$ & $89 \%$ & $83 \%$ \\
\hline
\end{tabular}

Berdasarkan tabel di atas dapat diketahui presentase ketuntasan hasil belajar peserta didik mengalami peningkatan di setiap siklusnya. Pada siklus satu muatan pelajaran IPA presentase ketuntasannya $67 \%$. Untuk siklus dua naik menjadi $89 \%$ dan untuk siklus tiga tetap bertahan $89 \%$. Sedangkan untuk muatan pelajaran Bahasa Indonesia pada siklus satu ketuntasan hasil belajar peserta didik $67 \%$. Untuk siklus dua naik menjadi $78 \%$ dan pada siklus ketiga naik lagi menjadi $83 \%$. Sedangkan untuk BI pada siklus satu presentasenya $67 \%$. Pada siklus dua nail menjadi $89 \%$. Dan pada siklus tiga naik lagi menjadi $83 \%$.

Peningkatan hasil belajar dengan menggunakan media Power Point Interaktif pada siklus 1 ke siklus 2 kemudian sampai ke siklus 3 menunjukkan adanya peningkatan. Peningkatan hasil belajar terjadi disebabkan penggunaan media Power Point Interaktif secara berbeda setiap siklusnya, sehingga kegiatan pembelajaran lebih menarik. Sesuai dengan kelebihan media Powerpoint yang dikemukakan oleh Daryanto (2010:164), yaitu pesan informasi yang dikemas secara visual akan lebih mudah dipahami peserta didik sehingga hasil belajar mereka akan meningkat. Dengan penambahan gambar yang menarik dalam tampilan Powerpoint, maka pesan atau informasi yang disampaikan akan mudah dipahami oleh peserta didik.

Untuk hasil pengamatan pada lembar observasi teman sejawat dapat di lihat dari tabel berikut:

\begin{tabular}{|c|c|c|c|c|}
\hline NO & $\begin{array}{c}\text { ASPEK } \\
\end{array}$ & \multirow{2}{*}{$\begin{array}{l}\text { SIKLUS } \\
1\end{array}$} & \multirow{2}{*}{$\begin{array}{l}\text { SIKLUS } \\
2\end{array}$} & \multirow{2}{*}{$\begin{array}{l}\text { SIKLUS } \\
3\end{array}$} \\
\hline A & MEMBUAT BERKAS POWER POINT & & & \\
\hline & $\begin{array}{l}\text { 1. Menampilkan kalimat yang jelas } \\
\text { mengenai materi pembelajaran }\end{array}$ & $\mathrm{Ya}$ & $\mathrm{Ya}$ & $\mathrm{Ya}$ \\
\hline & $\begin{array}{l}\text { 2. Menampilkan background gambar } \\
\text { yang mewakili materi pembelajaran }\end{array}$ & Ya & Ya & $\mathrm{Ya}$ \\
\hline & $\begin{array}{l}\text { 3. Menampilkan animasi yang mewakili } \\
\text { materi pembelajaran }\end{array}$ & Tidak & Ya & Ya \\
\hline & $\begin{array}{l}\text { 4. Menampilkan audio yang jelas } \\
\text { mewakili materi pembelajaran }\end{array}$ & Tidak & Tidak & $\mathrm{Ya}$ \\
\hline & $\begin{array}{l}\text { 5. Menyajikan simpulan melalui power } \\
\text { point }\end{array}$ & $\mathrm{Ya}$ & $\mathrm{Ya}$ & $\mathrm{Ya}$ \\
\hline
\end{tabular}

Kegiatan observasi dibantu oleh teman sejawat menggunakan lembar observasi pada siklus satu. Hasil observasi menggunakan table observasi menjelaskan bahwa tayangan Power Point sudah menampilkan kalimat yang jelas dan background gambar yang mewakili materi pelajaran, namun untuk animasi belum terlihat dan audio di dalam power point juga belum terdengar. Namun di akhir pembelajaran guru sudah menampilkan simpulan materi pelajaran. 
Pada siklus dua menjelaskan bahwa tayangan Power Point sudah menampilkan kalimat yang jelas dan background gambar yang mewakili materi pelajaran, animasi sudah mewakili materi dalam power point namun untuk audio di dalam power point juga belum terdengar. Di akhir pembelajaran guru sudah menampilkan simpulan materi pelajaran.

Dan pada siklus tiga tayangan Power Point sudah menampilkan kalimat yang jelas dan background gambar yang mewakili materi pelajaran, animasi sudah mewakili materi dalam power point dan audio di dalam power point juga sudah terdengar. Di akhir pembelajaran guru sudah menampilkan simpulan materi pelajaran.

Dari sini sudah terlihat bahwa peneliti mengalami peningkatan dalam memodifikasi tayangan Power point interaktif semenarik dan sejelas mungkin dari siklus satu sampai pada tahap siklus tiga.

Penelitian yang telah dilaksanakan merupakan penelitian tindakan kelas yang terdiri dari tiga siklus. Tiap siklus terdiri empat tahap. Pada siklus 1 peneliti sudah menerapkan media Powerpoint Interaktif, namun belum secara maksimal. Hal ini terlihat pada saat menampilkan animasi-animasi belum terlihat menarik. Untuk audio dalam media Powerpoint juga belum terdengar. Ketika siklus 2 dilaksanakan, pendidik tetap menggunakan media Powerpoint, namun media yang dibuat lebih simpel dengan menampilkan beberapa gambar dan video contoh hubungan antar makhluk hidup. Video yang ditampilkan merangsang peserta didik untuk aktif bertanya. Selain itu, peserta didik juga lebih paham mengenai materi yang disampaikan. Namun suara dalam video juga belum bisa terdengar secara jelas. Untuk hasil belajar juga mengalami peningkatan dari siklus 1 ke siklus 2. Pada siklus 1 hanya jumlah peserta didik yang mencapai KKM juga kurang dari 75\%, namun ketika siklus 2 dilaksanakan jumlah peserta didik yang mencapai KKM lebih dari 75\%. Agar hail belajar bia maksimal, peneliti melaksanakan siklus 3. Di siklus 3 ini peneliti berusaha memanagemen waktu sebaik mungkin untuk menghindari sinyal internet terputus di tengah jalan. Guru juda tidak menampilkan video, hanya Power Point Interaktif yang sudah bisa mewakili materi belajaran. Dari siklus tiga ini diperoleh peningkatan yang sangat baik. Baik dari hasil maupun keaktifan peserta didik selama proses pembelajaran. Sehingga dapat disimpulkan bahwa dengan adanya siklus 3 ini, penelitian dikatan berhasil dan tercapai semua indikator dalam penggunaan media pembelajaran Power Point Interaktif. Jadi kesimpulan dari paparan di atas, peserta didik mengalami peningkatan hasil belajar yang cukup memuaskan dari setiap pertemuan di setiap siklusnya. Minat belajar peserta didik juga meningkat.

\section{SIMPULAN}

Berdasarkan hasil penelitian dan uraian pembahasan maka dapat diambil kesimpulan sebagai berikut:

Penerapan penggunaan media Power Point Interaktif dapat meningkatkan hasil belajar peserta didik kelas V SDN Randuacir 03. Hal ini terlihat berdasarkan hasil observasi setiap siklusnya. Penggunaan media Power Point Interaktif dari siklus 1 ke siklus 2 juga terus diperbaiki sampai ke tahap siklus 3 . Hal ini terlihat dari keaktifan peserta didiknya dalam pelaksanaan pembelajaran siklus 1 , siklus 2 dan siklus 3 . Mereka terlihat antusias dan aktif bertanya dan menjawab pertanyaan dari guru. Hasil persentase rata-rata yang diperoleh dari kelulusan KKM juga meningkat terus meningkat di setiap siklusnya. Dari siklus 1 kelulusan dibawah $75 \%$ untuk mupel IPA dan Bahasa Indonesia. kemudian pada siklus 2 meningkat menjadi $89 \%$ dan $79 \%$ untuk kedua mupel tersebut. Dan siklus 3 menjadi $89 \%$ dan $83 \%$. 


\section{DAFTAR PUSTAKA}

Arshad, Azhar. (2013). Media Pembelajaran. Jakarta: Rajawali Pers.

BSNBP. (2006). Penyusunan KTSP Kabupaten/Kota Pnaduan Penyusunan Kurikulum Tingkat Satuan Pendidikan Jenjang Pendidikan Dasar dan Menengah. Jakarta: Departemen Pendidikan Nasional.

Burns, Anne. (2010). Doing Action Research in English Language Teaching. New York: Routledge.

Cohen, Louis, Lawrence Manion, and Keith Morrison. (2000). Research Methods in Education. New York: Routledge Falmer.

Daryanto. (2010). Media Pembelajaran. Yogyakarta: Gava Media.

Daryanto. (2011). Penelitian Tindakan Kelas dan Penelitian Tindakan Sekolah. Yogyakarta: Gava Media.

Departemen Pendidikan Nasional. (2004). Kurikulum 2004. Jakarta: Dirjen Pendiidkan Dasar dan Menengah.

Kemmis, S \& Mc Taggart, R. (1992). The Action Research Planner. Australia: Deakin University Press.

Madya, Suwarsih. (2007). Teori dan Praktik Penelitian Tindakan: Action Research. Bandung: Alfabeta.

Sudjana. (2005). Metoda Statistika. Bandung: PT: Tarsito Bandung.

Suharsimi Arikunto. (2005). Manajemen Penelitian. Jakarta: Rineka Cipta.

Suwarsih, Madya. (1994). Panduan Penelitian Tindakan Kelas. Yogyakarta: Lembaga Penelitian IKIP Yogyakarta.

T. Raka Joni, Kardiawarman dan Tisno J. (1998). Konsep Dasar Penelitian Tindakan Kelas (Classroom Action Research). Jakarta: Proyek Pengembangan Guru Sekolah Menengah.

Universitas Pendidikan Indonesia. (2007). Pedoman Penulisan Karya IImiah. Bandung: Universitas Pendidikan Indonesia.

https://id.wikihow.com/Membuat-Presentasi-Menggunakan-PowerPoint (diakses tanggap 13 Oktober 2020 pukul 19.32 WIB)

https://slideplayer.info/slide/1983475/ (diakses tanggap 13 Oktober 2020 pukul 19.47 WIB) 